\title{
A PROBLEMÁTICA DOS MONOPÓLIOS DAS INDÚSTRIAS DE MEDICAMENTOS E O DIREITO À SAÚDE: O CASO GLIVEC \\ THE PROBLEM OF MONOPOLY OF DRUG INDUSTRIES AND THE RIGHT TO HEALTH: THE GLIVEC CASE
}

Natália Zampieri"

Resumo: O presente artigo teve por fim comentar a decisão do Tribunal Superior de Madras, da Índia, a respeito de questão que envolve a patente do medicamento Glivec, fabricado pela empresa Novartis. Para tanto, fez-se uma breve retrospectiva do Caso Novartis AG versus União da Índia, explicando algumas questões que foram objeto de análise pelo Tribunal, por exemplo, a alteração legislativa indiana, a Declaração de Doha e o Acordo TRIPS. Além disso, foram feitas considerações a respeito das alegações da Novartis na defesa da importância da patente, da adaptação legislativa com o propósito do combate ao mecanismo denominado evergreening, bem como acerca de um relevante direito fundamental - o direito à saúde - usado como uma das justificativas da decisão do Tribunal. O estudo que se faz presente neste trabalho pretendeu, portanto, avaliar a controvérsia existente sobre a questão que circunda o tema do acesso aos medicamentos, considerando o direito de propriedade intelectual das indústrias farmacêuticas.

Palavras-chave: TRIPS. Medicamentos. Glivec. Índia. Direito à saúde.

\begin{abstract}
This article aimed to comment the decision of the High Court of Madras, India, on matter involving the patent for Glivec, manufactured by Novartis. It is about a brief review of the Case Novartis AG versus Union of India, in which will be explained some issues that have been considered by the Court, for example, the Indian legislative changes, the Doha Declaration and the TRIPS Agreement. Besides, some considerations were made about the allegations by Novartis in defense of the importance of the patent, the legal adaptation for the purpose of combating the called evergreening mechanism, as well as the respect of a relevant fundamental right - the right to health - used as justification to the Court's decision. The presented paper, therefore, aimed to assess existing controversy on the issue that revolves around access to drugs, in view of the intellectual property rights of pharmaceutical companies.
\end{abstract}

Keywords: TRIPS. Drugs. Gleevec. India. Right to health.

\footnotetext{
${ }^{*}$ Mestre em Direito Constitucional pela Universidade de Coimbra, Portugal; Doutoranda em Direito Público pela Universidade de Coimbra, Portugal; Pátio da Universidade, 3004-528, Coimbra, Portugal; Bolsista da Capes - Proc. n. BEX 0747/14-9; Capes, Ministério da Educação, 70040-020, Brasília, DF, Brasil; nataliazampieri@yahoo.com.br
} 


\section{Considerações introdutórias: exposição do caso}

O presente artigo teve como ponto de partida a análise do acórdão referente ao Caso Novartis versus União da Índia (HIGH COURT OF JUDICATURE AT MADRAS, 2007) proferido pelo Tribunal Superior de Madras.

Quando a Empresa Farmacêutica Novartis contestou a rejeição do pedido de patente para a droga Glivec (leucemia) no caso Novartis AG versus Índia, esta se tornou a primeira discussão relevante contra a nova Lei de Patentes da Índia.

Em 2005, a Índia fez as mudanças necessárias para deixar suas leis de propriedade intelectual em conformidade com o Acordo Relativo aos Aspectos do Direito da Propriedade Intelectual Relacionados com o Comércio (Adpic), mais conhecido como TRIPS, Trade-Related Aspects of Intellectual Property Rights. ${ }^{1}$

Entretanto, depois que a Índia alterou sua legislação em 2005, sua Lei de Patentes tornou-se preocupante pela existência de várias disposições consideradas controversas por aqueles cuja atividade empresarial faz uso de direitos do autor com o propósito de obter lucro.

O Glivec é usado para o tratamento da leucemia mieloide crônica (LMC). Em janeiro de 2006, foi recusada a concessão de uma patente da Novartis para o mesilato de imatinib, substância química do Glivec, em razão da carência de atividade inventiva e da falta de demonstração de aumento da eficácia do medicamento, com base na Seção 3 (d) da Emenda 2005.

Em razão da recusa da concessão da patente, a Novartis ajuizou ação no Tribunal Superior de Madras, em maio de 2006, contra o Governo indiano e contra vários fabricantes de medicamentos genéricos, entre outros, requerendo a declaração de inconstitucionalidade da Seção 3 (d) da Lei de Patentes (MINISTERY OF LAW AND JUSTICE, 2005) $)^{2}$ pela violação do art. 14 da Constituição da Índia (GOVERNMENT OF INDIA, 1949), ${ }^{3}$ afirmando ser a Seção arbitrária e imprecisa; bem como pelo desacordo dessa disposição com o TRIPS em razão da existência de incompatibilidade. Argumentou-se que a Seção alterada, como está escrita hoje, di-

\footnotetext{
1 O TRIPS é um acordo internacional integrante do conjunto de acordos assinados em 1994 e que encerrou a Rodada do Uruguai. É considerado o mais importante instrumento multilateral para a globalização das leis de propriedade intelectual.

2 "Amendment of section 33 . In section 3 of the principal Act, for clause (d), the following shall be substitued, namely:"(d) the mere discovery of a new form of a known substance which does not result in the enhancement of the known efficacy of that substance or the mere discovery of any new property or new use for a known substance or of the mere use of a known process, machine or apparatus unless such known process results in a new product or employs at least one new reactant.

Explanation. For the purposes of this clause, salts, esters, ethers, polymorphs, metabolites, pure form, particle size, isomers, mixtures of isomers, complexes, combinations and other derivatives of known substance shall be considered to be the same substance, unless they differ significantly in properties with regard to efficacy'."

3 "Right to Equality 14. The State shall not deny to any person equality before the law or the equal protection of the laws within the territory of India."
} 
verge de vários artigos do TRIPS, inclusive do art. 27 (ORGANIZACIÓN MUNDIAL DEL COMERCIO, 1994), ${ }^{4}$ que dispõem sobre patentes de invenção.

Ao Tribunal Superior de Madras foi proposto avaliar, portanto, as seguintes questões: primeiramente, discutiu-se sobre a competência dos tribunais da Índia para testar a validade da Seção 3 (d) sob violação do TRIPS, ponto que, entretanto, não será desenvolvido no presente estudo. ${ }^{5} \mathrm{~A}$ segunda questão avaliada se relaciona com a violação (ou não) da Seção 3 (d) da Lei de Patentes com o art. 14 da Constituição da Índia por motivos de imprecisão e arbitrariedade daquela em relação a esta.

Na decisão, o Tribunal rejeitou a argumentação da Novartis de que a Seção 3 (d) - que nega patentes para novos usos de substâncias conhecidas a menos que o titular possa demonstrar "aumento da eficácia conhecida" ou "diferindo significativamente em propriedades relacionadas à eficácia” - era ambígua e imprecisa. O Tribunal afirmou, ainda, que a Seção 3 (d) não viola o art. 14 da Constituição da Índia, não é arbitrária e tampouco confere poder desmedido ao órgão nacional controlador das patentes.

Embora as duas frases descritas e destacadas no parágrafo anterior não sejam explicitamente definidas, o Tribunal entendeu que era uma prática comum do legislador usar linguagem geral e abstrata, deixando aos Tribunais a atividade de interpretação do texto jurídico com base no contexto e nas circunstâncias apresentadas em cada caso.

Além disso, o Tribunal considerou que a Novartis era uma empresa sofisticada e que possuía o conhecimento tecnológico para compreender o significado

\footnotetext{
4 "Artículo 27 Materia patentable

1. Sin perjuicio de lo dispuesto en los párrafos 2 y 3 , las patentes podrán obtenerse por todas las invenciones, sean de productos o de procedimientos, en todos los campos de la tecnología, siempre que sean nuevas, entrañen una actividad inventiva y sean susceptibles de aplicación industrial. Sin perjuicio de lo dispuesto en el párrafo 4 del artículo 65, en el párrafo 8 del artículo 70 y en el párrafo 3 del presente artículo, las patentes se podrán obtener y los derechos de patente se podrán gozar sin discriminación por el lugar de la invención, el campo de la tecnología o el hecho de que los productos sean importados o producidos en el pais.

2. Los Miembros podrán excluir de la patentabilidad las invenciones cuya explotación comercial en su territorio deba impedirse necesariamente para proteger el orden público o la moralidad, inclusive para proteger la salud o la vida de las personas o de los animales o para preservar los vegetales, o para evitar daños graves al medio ambiente, siempre que esa exclusión no se haga meramente porque la explotación esté prohibida por su legislación.

3. Los Miembros podrán excluir asimismo de la patentabilidad:

a) los métodos de diagnóstico, terapéuticos y quirúrgicos para el tratamiento de personas o animales;

b) las plantas y los animales excepto los microorganismos, y los procedimientos esencialmente biológicos para la producción de plantas o animales, que no sean procedimientos no biológicos o microbiológicos. Sin embargo, los Miembros otorgarán protección a todas las obtenciones vegetales mediante patentes, mediante un sistema eficaz sui generis o mediante una combinación de aquéllas y éste. Las disposiciones del presente apartado serán objeto de examen cuatro años después de la entrada en vigor del Acuerdo sobre la OMC."

5 O Tribunal se considerou incompetente para decidir sobre a validade da Seção alterada e, consequentemente, não decidiu sobre a questão relacionada à conformidade ou não da Seção 3 (d) com o art. 27 do TRIPS. O Tribunal concordou com os argumentos dos Réus, nos seguintes termos: os advogados dos Réus afirmaram que o acórdão citado pelos Autores (um acórdão em que a Câmara dos Lordes, verificando que uma lei interna era incompatível com duas Diretivas do Conselho, declarou-se competente e decidiu a questão que havia sido colocada naquele caso concreto) não poderia ser aplicado no caso em questão, pois diferentemente da recepção das Diretivas do Conselho pela Inglaterra, o TRIPS não se torna obrigatório na Índia sem qualquer mediação legislativa nacional. Declararam, invocando também uma decisão para fundamentar tal afirmação, que os Tribunais nacionais indianos são incompetentes para avaliar a contestação de uma lei nacional pela suposta violação de um tratado internacional. O próprio TRIPS, no art. 64, prevê mecanismos específicos de solução de qualquer litígio decorrente do acordo.
} 
das expressões empregadas na seção alterada, como, por exemplo, a exigência de "eficácia reforçada".

Segundo o ponto de vista das empresas farmacêuticas, sua capacidade para garantir a proteção de patentes na Índia é importante para a criação de incentivos para pesquisas farmacêuticas; em contrapartida, afeta profundamente a indústria farmacêntica de medicamentos genéricos do país e os preços dos medicamentos disponíveis para uma população crescente e maioritariamente carente.

Este estudo pretendeu avaliar uma parte da controvérsia existente sobre a questão do acesso aos medicamentos e do direito de propriedade intelectual por parte das indústrias farmacêuticas.

Em um primeiro momento, realizou-se uma análise sobre a Declaração de Doha e as consequentes alterações dos ordenamentos jurídicos internos (em particular, da Índia), bem como os princípios e objetivos do TRIPS.

Em segundo lugar, foi feita uma abordagem sobre a alegação das indústrias farmacêuticas sobre a recusa das patentes de medicamentos afetar os investimentos em pesquisas, em contraposição aos preços dos medicamentos praticados no mercado.

A terceira seção do estudo pretendeu demonstrar a intenção da alteração da legislação indiana no que se refere ao combate do chamado evergreening. Finalmente, serão feitas algumas considerações sobre o direito à saúde no ordenamento jurídico indiano para compreender, fundamentalmente, a decisão do Tribunal de Madras no Caso Novartis.

\section{1 o impacto da Declaração de Doha em relação aos países em desenvolvimento e ao direito à saúde}

\subsection{A Rodada do Uruguai e a Legislação indiana}

Diante da Rodada do Uruguai, celebrada durante a vigência do Acordo Geral sobre Tarifas e Comércio (GATT), fundou-se a Organização Mundial do Comércio (OMC), cujos objetivos principais são institucionalizar o debate sobre o comércio mundial e servir como fórum para soluções de disputas comerciais. O Acordo TRIPS, por sua vez, compõe o Anexo 1-C do Acordo Geral da OMC, e visa tanto completar as deficiências do sistema da Organização Mundial de Propriedade Intelectual quanto vincular, em definitivo, os direitos de propriedade intelectual ao comércio internacional (MERCER, 2006, p. 190).

Verificou-se, entretanto, um período de transição das legislações nacionais em relação ao TRIPS, no sentido de que países que já ofereciam alguma proteção internamente deveriam passar a estender o direito de proteção para todos os países membros da OMC; bem como aqueles países que excluíam alguns produtos da proteção por patentes (fármacos e agrícolas), tiveram que começar a conceder garantias. 
Especificamente sobre o caso indiano, foi em 31 de dezembro de 1994 que o Presidente promulgou a Patents Ordinance, que emendou o Patent Act de 1970, no intuito de cumprir com o disposto no TRIPS no sentido de garantir o direito de patente e de comercialização exclusiva de produtos farmacêuticos (MERCER, 2006, p. 192). ${ }^{6}$ Entretanto, por ser um ato do Executivo, essa medida vigorou até 26 de março de 1995, seis semanas após o reestabelecimento das atividades parlamentares.

Logo após, o Governo indiano tentou aprovar uma Patents Bill, mas no meio do processo o Parlamento foi dissolvido, o que impossibilitou a prorrogação da validade da Ordinance. Dessa forma, a Índia chegou a ter legislação que protegia as parentes de fármacos, mas isso não se concretizou, sofrendo, inclusive, questionamentos por parte da OMC (MERCER, 2006, p. 195).

A Índia, portanto, teve que alterar sua legislação para permitir as patentes de produtos farmacêuticos; e assim o fez em 01 de janeiro de 2005. Para alcançar o texto de 2005, o Patent Act de 1970 passou por três alterações. A primeira alteração implementada foi no sentido do dever de fornecer um sistema para que os pedidos de patente pudessem ser apresentados durante o período de transição. A segunda alteração se relacionou com a prorrogação do prazo da vigência das patentes para 20 anos, com a modificação das exigências de licenciamento compulsório e com os encargos da prova por violação de patente.

Finalmente, em 2005, o Governo indiano realizou o seu mais recente passo para obedecer ao TRIPS e contextualizar as patentes de produtos farmacêuticos em âmbito nacional. A disponibilidade de proteção de patentes para produtos farmacêuticos, conforme exigido pelo art. 27.1 do TRIPS (e a proibição de discriminação quanto ao local de invenção), tem sido uma das principais diferenças entre os regimes de patentes dos países desenvolvidos e em desenvolvimento (LEE, 2008).

O Patents (Amendment) Áct de 2005 removeu a proibição de patentes de produtos farmacêuticos para os compostos, permitindo a qualquer empresa buscar a concessão de patentes na Índia. No entanto, outras disposições da Emenda de 2005 foram no sentido de limitar o alcance da proteção da patente do produto. Uma das novas disposições introduzidas é justamente a Seção 3 (d), a qual é objeto do litígio Novartis (LEE, 2008).

\subsection{Princípios fundamentais e objetivos do Acordo: o equilíbrio necessário entre propriedade intelectual e acessibilidade}

Geralmente, admite-se que os produtos farmacêuticos não podem ser considerados simples mercadorias por basicamente dois motivos: em primeiro lugar, porque os consumidores não estão em posição de julgar, por exemplo, a qualidade dos medicamentos e, por outro lado, é necessário que haja um sistema de controle e

${ }_{6}$ A promulgação de tal ato pelo Presidente é possível, de acordo com o art. 123 da Constituição indiana, pelo fato
de permitir legislar quando o Parlamento não estiver em sessão, nos casos em que existirem urgência e necessidade. 
vigilância por parte do Estado; em um segundo momento, porque os medicamentos desempenham um papel social de elevada importância, na medida em que fazem parte da viabilidade da realização de um direito humano fundamental - o direito à saúde. Pode-se considerar, dessa forma, o medicamento como um bem público, sublinhando o direito de todo o cidadão ao seu acesso. ${ }^{7}$

Os parágrafos gerais do TRIPS (preâmbulo e disposições gerais) destacam a necessidade de promover a proteção adequada e efetiva dos direitos de propriedade intelectual, mas a proteção desses direitos não é uma obrigação absoluta nem exclusiva.

Os objetivos do Acordo TRIPS, conforme estabelecido no art. 7, e a disposição contida no art. 8 (1) em relação aos princípios, foram propostos pelo Grupo dos 14 com o objetivo de preservar certa flexibilidade na adoção e aplicação da legislação de propriedade intelectual. Assim, o art. 8 (1) permite aos Estados-membros, ao formular ou emendar suas leis e regulamentos nacionais sobre direitos de propriedade intelectual, adotarem as medidas necessárias para proteger a saúde pública e a nutrição e promover o interesse público em setores de importância vital para o seu desenvolvimento socioeconômico e tecnológico (CORREA; YUSUF, 2008, p. 12).

A ampla margem de flexibilidade legislativa concedida pelo art. 8.1, mais recentemente, foi confirmada por meio da Declaração de Doha sobre o Acordo TRIPS e saúde pública, adotados pela Quarta Conferência Ministerial da OMC em novembro de 2001. O parágrafo $4^{\circ}$ da Declaração expressa essa flexibilidade quanto à saúde pública, nos seguintes termos:

[...] nós concordamos que o Acordo TRIPS não impede e não deve impedir que os membros tomem medidas para proteger a saúde pública. Assim, enquanto reiteramos nosso compromisso com o Acordo TRIPS, nós afirmamos que o acordo pode e deve ser interpretado e implementado de modo a apoiar o direito dos membros da OMC de proteger a saúde pública e em especial para promover acesso a medicamentos para todos. (CORREA; YUSUF, 2008, p. 13-14).

Sensibilizados com a situação vivida na África por milhões de pessoas sem acesso a tratamentos ou medicamentos eficazes para o combate do avanço da epidemia da Síndrome da Imunodeficiência Adquirida (SIDA) ou Acquired Immunodeficiency Syndrome (AIDS), e incentivados por uma emblemática decisão da Suprema Corte Sul-Africana que, em 2001, entendeu constitucional uma lei local, de 1997, que permitia a importação de medicamentos a preços menores, independentemente da existência de direitos de propriedade, originalmente questionada por cerca de 39 empresas farmacêuticas americanas; os Ministros reunidos no Qatar declararam que as cláusulas do TRIPS deveriam ser interpretadas evolutivamente, à luz do ob-

\footnotetext{
7 A questão da acessibilidade é muito importante, no sentido de que as políticas aplicadas devem se encaminhar a colocar os medicamentos ao alcance de todos aqueles que necessitam, a preços acessíveis. E essa foi uma das metas do GATT: justamente eliminar os obstáculos ao comércio para que os consumidores tenham maior acesso possível a todos os bens disponíveis.
} 
jeto e da finalidade do Acordo, e em conformidade com o expresso nos seus objetivos e princípios, reduzindo distorções e removendo obstáculos ao livre e legítimo comércio internacional sem esquecer os objetivos de políticas públicas nacionais de desenvolvimento (CORREA, 2005, p. 30).

A Declaração de Doha reconhece a gravidade dos problemas de saúde pública que afligem países pouco desenvolvidos e em desenvolvimento, destacando os problemas que decorrem da AIDS, da tuberculose, da malária e de outras epidemias - mas não se limitando a eles. A Declaração reflete as preocupações desses países sobre as implicações do Acordo TRIPS em relação à saúde pública em geral, sem se restringir a determinadas doenças. Embora reconheça o papel da proteção à propriedade intelectual "para o desenvolvimento de novos medicamentos", a Declaração se preocupa especificamente com os possíveis efeitos sobre os preços. Afirma que o Acordo TRIPS não pretende e não deve impedir que seus membros tomem medidas para proteger a saúde pública, e, portanto, precisa ser interpretado nesse sentido (CORREA, 2005, p. 32-35).

É certo que, em decorrência da Declaração de Doha, os Estados cujas populações se encontram mais afetadas por doenças infectocontagiosas ou expostas a uma maior probabilidade de desequilíbrio (nomeadamente os países em desenvolvimento), gozam de maior discricionariedade legislativa quanto à adoção de medidas destinadas a promoverem o acesso mais rápido e economicamente mais vantajoso aos cuidados da sáude, ainda quando os farmácos se encontram sujeitos a direitos de patente, destacando-se a possibilidade de modelar o regime nacional das licenças obrigatórias e das importações paralelas já que a adoção do Acordo TRIPS no direito interno deve se realizar por meio de uma adequada tutela da saúde pública.

Dotada de valor retórico, e não normativo, a Declaração de Doha reconhece que patentes podem configurar um obstáculo ao acesso a medicamentos em países em desenvolvimento (CORREA; YUSUF, 2008, p. 14; LEONARDOS; OSWALD, 2007, p. 14).

Tanto o art. 7 quanto o art. 8 (2) indicam claramente o caráter subordinado da proteção dos direitos de propriedade intelectual a objetivos de política pública em outras esferas da atividade do Estado, especialmente na do bem-estar social e econômico, que depende em parte das políticas sociais e sanitárias. O art. 7 salienta assim mesmo a obrigatoriedade de considerar os interesses de todos os setores envolvidos (ORGANIZACIÓN MUNDIAL DEL COMERCIO, 1994). ${ }^{8}$

$\mathrm{O}$ art. 8 (1) autoriza a adaptação das normativas nacionais aos objetivos fundamentais de política pública que os governos tiverem fixadas em determinados setores, com a condição de que não sejam contrárias às disposições do Acordo. Entre esses objetivos faz-se especial menção à saúde pública e à nutrição, o que equivale a

\footnotetext{
8 "Artículo 7 (Objetivos) La protección y la observancia de los derechos de propiedad intelectual deberán contribuir a la promoción de la innovación tecnológica y a la transferencia y difusión de la tecnología, en beneficio recíproco de los productores y de los usuarios de conocimientos tecnológicos y de modo que favorezcan el bienestar social y económico y el equilibrio de derechos y obligaciones."
} 
um reconhecimento expresso de medidas que poderiam ser adotadas para garantir a acessibilidade. Convém citar também o art. 8 (2), o qual uma vez mais expressa a necessidade de atribuir uma interpretação equilibrada às medidas de proteção dos direitos de propriedade intelectual. Esses direitos devem ser protegidos de maneira que não gerem abusos prejudiciais para o necessário equilíbrio entre objetivos nacionais e interesses setoriais garantidos pelo Estado (ORGANIZACIÓN MUNDIAL DEL COMERCIO, 1994). ${ }^{9}$

Com esse propósito, o art. 1, Natureza e alcance das obrigações, (1) apresenta elevada importância por estabelecer que os Estados-membros não estão obrigados a conceder uma proteção maior do que aquela estipulada pelo Acordo. Esse artigo reconhece que os Estados-membros têm absoluta liberdade no que diz respeito aos métodos utilizados para acomodar as obrigações que tenham sido subscritas dentro do marco de seus respectivos sistemas e práticas jurídicas (ORGANIZACIÓN MUNDIAL DEL COMERCIO, 1994). ${ }^{10}$

Essas disposições gerais estão incluídas no Acordo para propiciar um equilíbrio entre os direitos dos titulares de patentes e suas obrigações sociais. A partir de uma perspectiva da política social e sanitária, estas disposições abrem a possibilidade de se estabelecerem normativas nacionais que considerem o imperativo da garantia do direito dos cidadãos ao melhor acesso possível aos medicamentos.

\section{A alegação das empresas farmacêuticas sobre o incentivo em pesquisas versus preço dos medicamentos}

A Novartis é uma das líderes mundiais em produtos farmacêuticos e produtos para a saúde do consumidor. No ano 2001, por exemplo, as divisões do grupo totalizaram um faturamento de 19 bilhões de dólares e lucro líquido de 4,2 bilhões de dólares, tendo investido aproximadamente 2,5 bilhões em pesquisa e desenvolvimento (NOVARTIS, 2002).

É possível afirmar que os direitos de propriedade intelectual se baseiam na ideia de que deve ser garantido aos inventores de determinado bem o direito de usar e dispor de sua invenção, com o intuito tanto de recuperar o investimento despendi-

\footnotetext{
9 “Artículo 8 (Principios) 1. Los Miembros, al formular o modificar sus leyes y reglamentos, podrán adoptar las medidas necesarias para proteger la salud pública y la nutrición de la población, o para promover el interés público en sectores de importancia vital para su desarrollo socioeconómico y tecnológico, siempre que esas medidas sean compatibles con lo dispuesto en el presente Acuerdo. 2. Podrá ser necesario aplicar medidas apropiadas, siempre que sean compatibles con lo dispuesto en el presente Acuerdo, para prevenir el abuso de los derechos de propiedad intelectual por sus titulares o el recurso a prácticas que limiten de manera injustificable el comercio o redunden en detrimento de la transferencia internacional de tecnología."

10 "Artículo 1 (Naturaleza y alcance de las obligaciones) 1. Los Miembros aplicarán las disposiciones del presente Acuerdo. Los Miembros podrán prever en su legislación, aunque no estarán obligados a ello, una protección más amplia que la exigida por el presente Acuerdo, a condición de que tal protección no infrinja las disposiciones del mismo. Los Miembros podrán establecer libremente el método adecuado para aplicar las disposiciones del presente Acuerdo en el marco de su propio sistema y práctica jurídicos."
} 
do quanto de perceber lucro equivalente à revelação da sua criação para a sociedade (LYARD, 2006, p. 32).

A patente é título de propriedade concedido pelo Estado. Por meio dela, o Estado confere aos inventores ou à empresa um direito exclusivo de exploração da invenção protegida. A lógica econômica de tal mecanismo de proteção consiste na ideia de que os lucros proporcionados pela licença de produção de um produto patenteado garantam ao detentor da patente o reinvestimento em pesquisa e desenvolvimento de novos produtos (LYARD, 2006, p. 32).

Os genéricos são medicamentos identificados pelo nome de seu princípio ativo, ainda que sem concordância dos donos das respectivas patentes, e são mais econômicos do que os seus equivalentes com marca registrada. A Índia é o principal produtor mundial de genéricos a baixo custo de medicamentos patenteados (CAVALHEIRO, 2006, p. 97-98).

Mais de 20 mil pessoas usam o medicamento genérico do Glivec na Índia. Sabe-se que enquanto o produto fabricado pela empresa suíça custa cerca de $€$ 2.000,00 (um comprimido por dia durante um mês), o genérico sai por $€ 150,00$ (RONCAGLIA, 2007).

A necessidade da redução dos custos da saúde e a importância do desenvolvimento de um mercado de medicamentos mais acessíveis aos cidadãos e mais baratos para o Estado, ao aconselharem o aumento da concorrência entre as empresas farmacêuticas e a diminuição da exclusividade, fortalecem a liberdade de comercialização, designadamente dos medicamentos genéricos.

Entretanto, ocorre que aqueles que defendem as empresas farmacêuticas acreditam que o estímulo da produção de medicamentos genéricos, aliado à dificuldade que as leis nacionais, nomeadamente dos países em desenvolvimento, proporcionam na tentativa da obtenção da patente de um medicamento por essas empresas, podem, em vez de contribuir positivamente para a saúde pública, acabar por afetar o estímulo à invenção.

Carvalho (2005, p. 146), por exemplo, reconhece que os países subdesenvolvidos têm sérios problemas de acesso a medicamentos em razão da precariedade na condição fincanceira de compra desses medicamentos. Entretanto, todos os países, tanto os desenvolvidos quanto os em desenvolvimento, possuem um problema ainda mais sério relativamente à falta de acesso a drogas que ainda não existem. Alguns doutrinadores entendem que as patentes de produtos farmacêuticos são um fator essencial, no sentido econômico, para financiar pesquisas que visem criar compostos para o combate ou a cura de outras inúmeras doenças.

Todavia, é possível tecer algumas considerações que se contrapõem a esse argumento, considerando-se, por exemplo, a questão do Glivec.

As patentes concedem monopólios locais por certo período de tempo às empresas que as detêm, podendo evitar que outras empresas produzam ou vendam o medicamento naquele país durante a vigência da patente, a qual, segundo as regras da OMC, é concedida pelo tempo mínimo de 20 anos. Dessa forma, as empresas pos- 
suidoras da patente de determinado medicamento em um país praticam preços em um mercado cuja competição não existe.

Observando-se, por exemplo, que em 2001 a Novartis totalizou um faturamento de 19 bilhões de dólares e investiu aproximadamente 2,5 bilhões em pesquisas, conforme já afirmado, bem como, por exemplo, em 2005, investiu 3,5 bilhões em pesquisas em relação a um faturamento de 32,2 bilhões de dólares (ISTO É DINHEIRO, 2006), a fundamentação tanto das empresas farmacêuticas quanto de alguns doutrinadores na defesa da importância das patentes como justificativa para a viabilidade de futuras pesquisas científicas para a criação de drogas de melhor efeito pode ser, por vezes, ilógica.

\section{0 combate do evergreening pela nova alteração da legislação indiana e suas consequências}

O Tribunal indiano também rejeitou o argumento de que a Seção 3 (d) foi decretada de forma arbitrária pelo Legislativo. A Novartis argumentou que a real razão da Seção 3 (d) não era a mesma que o inicialmente proposto ao Parlamento. O Tribunal decidiu que a Seção 3 (d) não foi decretada arbitrariamente. Os debates revelaram que havia um medo generalizado de que as alterações propostas anteriormente negariam aos cidadãos indianos o acesso a medicamentos mais baratos, e abririam a possibilidade de evergreening.

O Governo indiano introduziu a Seção 3 (d) para evitar que multinacionais farmacêuticas estendam a vida de uma patente, já que essas empresas, muitas vezes, prolongam a proteção por patentes mediante a obtenção de patentes em separado de um único produto, retardando ou impossibilitando a introdução dos medicamentos genéricos no mercado.

A Seção $3(d)$ foi então considerada a "salvaguarda da saúde pública" e visa impedir o tal chamado evergreening.

O evergreening é uma prática em que empresas farmacêuticas agem na tentativa de estender a proteção por patentes em diversas situações criadas, como, por exemplo:

a) novos pedidos de patente por outras propriedades da mesma substância ativa;

b) novas indicações terapêuticas para a mesma substância;

c) casos em que, quando se aproxima a caducidade dessas patentes, elas apresentam pedidos de patentes de processos relativos à fabricação do mesmo produto;

d) casos em que as empresas lançam um medicamento de segunda geração, tendo previamente depositado um novo pedido de patente;

e) também casos em que a própria empresa fabricante do medicamento de referência que lança no mercado um pseudogenérico (a empresa tenta 
comercializar uma versão genérica do primeiro pouco tempo antes da caducidade da patente, criando uma rede de distribuição, seja por intermédio de contratos de licença seja mediante criação de sociedades em cujo capital social participa majoritariamente) (MARQUES, 2008, p. 76-89).

Outra relevante previsão que pode ser analisada com a Seção 3 (d), é a Seção 2 (1) (j) que determina o conceito de invenção, considerando ser um "[...] new product or process involving an inventive step and capable of industrial application." Nessa mesma linha de raciocínio, define-se, na alínea (ja), que um "[...] 'inventive step' means a feature of an invention that involves technical advance as compared to the existing knowledge or having economic significance or both and that makes the invention not obvious to a person skilled in the art." (MINISTERY OF LAW AND JUSTICE, 2005).

Michel Lotrowska, representante da Campanha de Acesso a Medicamentos Essenciais do Médicos Sem Fronteiras no Brasil, afirma que a patente original do Glivec é de 1992, época em que nem a Índia nem o Brasil concediam patentes de produtos farmacêuticos. Pela Lei de Patentes de 2005, o Governo tem que analisar todos os pedidos de patentes depositados desde 1995. "A patente inicial da real inovação do Glivec data de 1992, antes da Lei de Patentes na Índia. Por isso, a molécula original não foi patenteada. A mera modificação que fizeram depois em 1996 não é patenteável segundo a lei indiana porque foi uma pequena modificação", explica Lotrowska (RONCAGLIA, 2007).

Não existe patente internacional ou global. Os pedidos de patentes são examinados pelos escritórios de patentes de cada país, que decidem se um medicamento particular deve ou não ser patenteado com base nas leis nacionais. Nesse sentido, a Índia, ao alterar sua lei de patentes para que ficasse em conformidade com as regras estipuladas pelo TRIPS, conseguiu desenvolver o texto de uma norma jurídica em que o número de patentes concedidas estivesse estritamente relacionado à real inovação que, na verdade, é o raciocínio inicial do sistema de concessão de patentes.

A lei indiana defende que as patentes somente devem ser concedidas aos medicamentos que realmente são novos e inovadores, o que exclui a possibilidade da obtenção de uma patente nos casos em que tais medicamentos revelam pequenas alterações em combinações ou fórmulas de medicamentos já existentes.

Portanto, a Seção $3(\mathrm{~d})$ tentou regular a concessão de tais patentes, limitando o alcance de proteção disponível para os derivados de substâncias conhecidas e novas utilizações das substância conhecidas, já que o art. 27 (1) do TRIPS afirma que "[...] poderão ser obtidas patentes para quaisquer invenções, quer seja de produtos ou processos, em todos os domínios da tecnologia, desde que sejam novas, envolvam uma atividade inventiva e sejam susceptíveis de aplicação industrial." 


\section{$4 \mathrm{O}$ direito à saúde no ordenamento jurídico indiano}

A Índia é considerada por muitos a maior democracia do mundo. Apesar da maioria dos componentes da Assembleia Constituinte, quando da elaboração da Constituição, ser originárias da elite indiana, havia um entendimento consciente de que se fazia necessária a criação de uma Constituição a qual, além de proteger os direitos e liberdades individuais, também promovesse os interesses dos "mais fracos" e destituídos da sociedade (BALAKRISHNAN, 2008).

O Poder Judiciário, independente, encontra-se no centro da estrutura de controle de constitucionalidade, não apenas garantindo um sistema altamente confiável de freios e contrapesos entre os outros poderes, mas também funcionando como instrumento de mudança e desenvolvimento social. Em várias situações, o Judiciário afirmou sua posição não apenas como protetor da Constituição, mas como um órgão que age com cautela na interpretação dos dispositivos constitucionais de maneira dinâmica, vislumbrando atender às necessidades dos tempos atuais (BALAKRISHNAN, 2008), conforme, inclusive, verificou-se na decisão do Caso Novartis.

Os Tribunais da Índia têm enfrentado alguns litígios sobre questões que envolvem a fronteira entre os direitos fundamentais e os objetivos da garantia da justiça social, e o caso em questão pode ser considerado um desses exemplos.

Os direitos fundamentais estão inseridos na Parte III da Constituição da Índia, ${ }^{11}$ tendo como característica mais importante a prestação, ao Judiciário, de um conjunto de critérios bem definidos para regular as relações entre os cidadãos e o Governo - bem como entre os próprios cidadãos - interpretando esses direitos não somente em uma dimensão negativa, mas também positiva.

Consta no art. 47, da Constituição da Índia, o dever do Estado em elevar o nível de nutrição e padrão de vida, além de melhorar as condições da saúde pública (GOVERNMENT OF INDIA, 1949). Esse artigo consta da Parte IV da Constituição, que trata dos "Princípios Diretivos da Política do Estado" (relativamente aos direitos socioeconômicos que visam à criação de uma sociedade igualitária).

Um ponto interessante sobre esses princípio diretivos é o fato de não poderem ser apreciados pelo Judiciário, em um sentido "ativista", devendo servir apenas de base para os atos do Executivo e do Legislativo (BALAKRISHNAN, 2008), justamente o que se verificou na decisão do caso em questão.

\footnotetext{
11 Resumidamente, o art. 14 da Constituição da Índia estabelece uma garantia de igual proteção perante a lei; o art. 15 proíbe a discriminação com base em religião, raça, casta, classe e gênero - mas, ao mesmo tempo, permite que o Estado propicie o avanço das mulheres e de outros segmentos da sociedade "socialmente e educacionalmente" atrasados, formando a base das políticas de "ações afirmativas"; o art. 16 cria para o Estado a obrigação de garantir imparcialidade em questões relativas ao emprego público. $\mathrm{Na}$ tentativa de aliviar as desigualdades sociais preponderantes, o art. 17 proíbe a prática da "intocabilidade", enquanto o art. 18 aboliu todos os títulos (com exceção dos títulos militares e acadêmicos). $\mathrm{O}$ art. 19 salvaguarda as liberdades dos indivíduos, tal como a liberdade de expressão, de reunião, de associação, de movimento dentro do país e a liberdade de buscar uma profissão. Os arts. 20,21 e 22 juntos constituem os direitos do devido processo legal. O art. 23 proíbe o tráfico de seres humanos e outras formas de trabalho forçado, enquanto o art. 24 proíbe o emprego de crianças menores de 14 anos em fábricas, minas e outros tipos de atividades perigosas. Os arts. 25 a 30 constituem as "garantias religiosas".
} 
Diante do disposto no art. 47 da Constituição da Índia, o Legislativo alterou a Lei de Patentes nacional, criando o texto da Seção 3 (d), considerando tanto o ordenamento jurídico interno quanto suas obrigações internacionais decorrentes ao TRIPS. Dessa forma, o Legislativo fez uso de um dos "Princípios Diretivos da Política do Estado" que, posteriormente, veio a ser questionado perante o Judiciário (controle de constitucionalidade concreto), não se verificando, por esse motivo, um ativismo inicial do Judiciário na implementação de norma constitucional.

A saúde é um bem coletivo e, ao mesmo tempo, um direito fundamental social. Os chamados direitos fundamentais sociais, além de possuírem uma dimensão individual subjetiva, também operam na esfera objetiva transpessoal, como decisão valorativa vinculante e como condição da democracia. Em algumas situações, resulta em medidas de organização do poder e em procedimentos de deliberação; em outras, no dever de providenciar meios reais de vida digna (HÄBERLE apud NASCIMENTO, 2008, p. 906).

Segundo Canotilho e Moreira (2007, p. 825), o direito à proteção da saúde é composto por uma dimensão positiva e outra negativa. Se, por um lado, vislumbra-se o direito de exigir, tanto do Estado quanto de terceiros, que se abstenham de praticar atos que prejudiquem a saúde, por outro lado, deparamo-nos com o direito às medidas e prestações estaduais, com o intuito de prevenir doenças e possibilitar seu tratamento.

Sarlet (2003, p. 121) equipara vida digna à vida saudável e aproxima os conceitos de qualidade de vida e dignidade da pessoa humana, afirmando que o completo bem-estar físico, mental e social densifica o princípio da dignidade humana, pois não é possível imaginar que condições de vida insalubres e inadequadas sejam aceitas como conteúdo de uma vida com dignidade.

Em um plano normativo internacional, pode-se mencionar a saúde como um dos direitos humanos expressos na Declaração Universal dos Direitos Humanos, de 1948 (NAÇÕES UNIDAS NO BRASIL, 1948), bem como explicitado pelo Pacto Internacional de Direitos Econômicos, Sociais e Culturais, de 1966 (ASSEMBLÉIA GERAL DAS NAÇÕES UNIDAS, 1966). Ainda que não estivesse expresso, o direito à saúde certamente poderia ser compreendido em conjunto com a previsão da tutela jurídica dos direitos à vida e à integridade física e corporal enquanto direito fundamental implícito.

Nesse sentido, somando-se os debates mencionados neste estudo, é possível compreender que a escassez dos recursos financeiros demonstra que os direitos fundamentais possuem uma dimensão econômica comum atrelada aos custos exigidos para que sejam concretizados. Holmes e Sunstein (2000, p. 94), analisando Dworkin, acentuam que levar a sério os direitos significa levar a sério a escassez, pois a efetividade dos direitos está submetida a razões bastante naturais, como são as restrições orçamentárias.

Conforme afirma Trubek (apud PIOVESAN 2003, p. 236), os direitos sociais, enquanto social welfare rights, implicam a visão de que o Governo tem a obrigação 
de garantir adequadamente tais condições para todos os indivíduos. A ideia de welfare denota a responsabilidade imputada ao Estado concernente à garantia e implementação das condições de bem-estar geral, especialmente pela realização dos direitos elencados no Pacto Internacional de Direitos Econômicos, Sociais e Culturais, bem como na própria Constituição.

Os medicamentos, intrinsecamente ligados à manutenção da saúde da população, constituem elemento importante da política sanitária de um Estado. Produtos de primeira necessidade, os medicamentos alcançam o patamar de bem público, necessitando, nesse aspecto, maior controle, zelo e atenção por parte do Estado nas políticas de distribuição, fiscalização e preços, entre outros fatores que atuam no acesso aos medicamentos conforme já abordado no presente estudo.

De forma especial, ao longo das décadas, a Corte Suprema da Índia tem afirmado que tanto os direitos fundamentais quanto os princípios diretivos devem ser interpretados de forma harmônica. Observou-se no Caso Kesavananda Bharati que os princípios diretivos e os direitos fundamentais se complementam e almejam a revolução social e o estabelecimento de um Estado de bem-estar social (mencionados também no Preâmbulo da Constituição). Ademais, no Caso Unni Krishnan, J.P. versus o estado de Andhra Pradesh, o Juiz Jeevan Reddy declarou: "Os dispositivos das Partes III e IV são suplementares e complementares entre si e não se excluem uns aos outros e os direitos fundamentais não são mais do que um meio para se alcançar a meta indicada na Parte IV." (BALAKRISHNAN, 2008).

Essa política de harmonizar os direitos fundamentais e os princípios diretivos foi bem sucedida em grande parte. Por exemplo, a Corte Suprema recorre aos objetivos dos direitos socioeconômicos a fim de interpretar o direito à "vida e à liberdade pessoal" como um direito que contempla o "direito à subsistência e à moradia", o "direito à saúde", e o "direito a um meio ambiente limpo", entre outros (BALAKRISHNAN, 2008).

O Tribunal Superior de Madras, que proferiu a sentença no Caso Novartis versus Índia, afirmou não haver ofensa constitucional da Seção 3 (d) que alterou a Lei de Patentes de 1970, não violando, por conseguinte, o art. 14, da Constituição da Índia. Foram observados alguns pontos em análise, nomeadamente um dos principais objetivos que a Lei vislumbrava, ou seja, evitar o evergreening, facilitando, por conseguinte, o acesso dos cidadãos aos medicamentos e possibilitando que o Estado cumpra sua obrigação constitucional de prestar bons cuidados de saúde aos seus cidadãos.

\section{Reflexões finais}

O Caso Novartis reflete, na prática, um dos possíveis resultados que podem ser gerados a partir da adoção de alterações legislativas sobre propriedade intelectual, por países em desenvolvimento, após as orientações mencionadas em decorrência da Rodada de Doha. 
A Índia é um estudo de caso digno de nota porque a sua imensa população está rapidamente se transformando em uma força global. Sua vasta indústria de medicamentos genéricos, que fornece drogas para os países desenvolvidos e em desenvolvimento ao redor do mundo, também aumentou os incentivos em R\&D e a qualificação de trabalhadores.

Outros países mantêm um olhar atento sobre como a lei de patentes da Índia está se desenvolvendo, e estão considerando a adoção de disposições semelhantes à Seção $3(\mathrm{~d})$ em suas leis nacionais.

Por fim, conclui-se que encontrar um ponto de equilíbrio entre o direito de propriedade intelectual, o direito à saúde, o combate ao evergreening, o incentivo a pesquisas e a acessibilidade dos medicamentos à população, apesar de ser uma tarefa difícil, provavelmente não é impossível.

\section{Referências}

BALAKRISHNAN, Konakuppakatil Gopinathan. A prática do controle de constitucionalidade nos dias de hoje. Palestra proferida no Supremo Tribunal Federal do Brasil, 2008. Disponível em: < http://www.stf.jus.br/arquivo/cms/bicentenarioPalestra/anexo/IndiaPortugues.pdf $>$. Acesso em: 05 jun. 2010.

CANOTILHO, José Joaquim Gomes; MOREIRA, Vital. Constituição da República Portuguesa Anotada. Coimbra: Coimbra Editora, 2007.

CARVALHO, Nuno Pires. The TRIPS Regime of Patent Rights. The Netherlands: Kluwer Law International, 2005.

CAVALHEIRO, Rodrigo da Costa Ratto. O monopólio e as Multinacionais Farmacêuticas. Itu: Ottoni, 2006.

CORREA, Carlos C. O acordo TRIPS e o acesso a medicamentos nos países em desenvolvimento. Revista Internacional de Direitos Humanos, São Paulo, ano 2, n. 3, 2005 .

CORREA, Carlos M.; YUSUF, Abdulqawi A. (Ed.). Intellectual Property and International Trade: the TRIPS Agreement. Austin: Wolters Kluwer, 2008.

GOVERNMENT OF INDIA. Ministery of Law and Justice. The Constitution of India. 1949. Disponível em: < http://lawmin.nic.in/coi/coiason29july08.pdf>. Acesso em: 01 jun. 2010.

HIGH COURT OF JUDICATURE AT MADRAS. Novartis AG. vs. Union of India, dated August 6. 2007. Disponível em: <http://www.scribd.com/doc/456550/High-Court-order-Novartis-Union-of-India >. Acesso em: 01 jun. 2010. 
HOMES, Stephen; SUNSTEIN, Cass R. The cost of rights: why liberty depends on taxes. New York: W.W. Norton, 2000.

ISTO É - DINHEIRO. A Fórmula Novartis. 2006. Disponível em: < http://www.istoedinheiro.com.br/noticias/4482_A+FORMULA+NOVARTIS > . Acesso em: 02 jun. 2010 .

LEE, Linda L. Trials and TRIPS-ulations: Indian Patent Law and Novartis AG v. Union of India. In: University of California Berkeley Technology Law Journal. Annual Review: Intellectual Property: Patent, 2008. Disponível em: < http://www.lexisnexis.com/us/lnacademic/results/docview/docview.do?docLinkInd=true\&risb $=21$ T9497151140\&format $=$ GNBFI\&sort $=$ RELEVANCE\&startDocNo $=1 \&$ resultsUrlK ey=29_T9497151145\&cisb=22_T9497151144\&treeMax =true\&treeWidth $=0 \&$ selR CNode $\overline{I D}=8 \&$ nodeStateId $=4 \overline{1} 1$ en_US, $1,2 \&$ docsInCategory $=2 \& \mathrm{csi}=168984 \&$ doc $\mathrm{No}=1>$. Acesso em: 05 jun. 2010 .

LEONARDOS, Luis; OSWALD, Maria Cecília. Direito de Patentes: uma proposta de filtragem constitucional. Revista da Associação Brasileira da Propriedade Intelectual, n. 86, jan./fev. 2007.

LYARD, Maria Alice Paim. Patentes de Medicamentos: questões atuais. Revista da Associação Brasileira de Propriedade Intelectual, n. 82, maio./jun. 2006.

MERCER, Henrique da Silva. O processo de acesso ao TRIPS, a relação do Acordo com as questões de saúde pública e a CDB e os Acordos TRIPS-PLUS. Revista Brasileira de Direito Internacional, Curitiba, v. 4, n. 4, jul./dez. 2006.

MINISTERY OF LAW AND JUSTICE. The Patents (Amendment) Act. 2005. Disponível em: <http://www.patentoffice.nic.in/ipr/patent/patent_2005.pdf>. Acesso em: 01 jun. 2010.

NAÇÕES UNIDAS NO BRASIL. Declaração dos Direitos Humanos. 1948. Disponível em: <http://www.onu-brasil.org.br/documentos_direitoshumanos.php>. Acesso em: 05 jun. 2010.

NASCIMENTO, Rogério José Bento Soares. Concretizando a Utopia: problemas na efetivação do direito a uma vida saudável. In: NETO, Cláudio Pereira de Souza (Coord.); SARMENTO, Daniel (Coord.). Direitos Sociais: fundamentos, judicialização e direitos sociais em espécie. Rio de Janeiro: Lumen Juris, 2008.

NOVARTIS. Comunicado à imprensa: O medicamento Glivec (Mesilato de imatinib) da Novartis é agraciado com o International Galien Prize de inovação terapêutica. 2002. Disponível em: < http://novartis.pulso.com.br/publishernovartis/swit-novartis/ arquivos_inst/premio.pdf $>$. Acesso em: 02 jun. 2010. 
ORGANIZACIÓN MUNDIAL DEL COMERCIO. Acuerdo de La Ronda Uruguay: ADPIC. 1994. Disponível em: < http://www.wto.org/spanish/docs_s/legal_s/27-trips_03_s.htm >. Acesso em: 01 jun. 2010.

PIOVESAN, Flávia. Proteção internacional dos direitos econômicos, sociais e culturais. In: SARLET, Ingo Wolfgang (Org.). Direitos Fundamentais Sociais: estudos de direito constitucional, internacional e comparado. Rio de Janeiro: Renovar, 2003.

REMÉDIO MARQUES, João Paulo Fernandes. Medicamentos versus patentes: estudos de propriedade industrial. Coimbra: Coimbra Editora, 2008.

RONCAGLIA, Daniel. Novartis luta para preservar patente de remédio na Índia. 2007. Disponível em: <http://www.conjur.com.br/2007-mar-06/novartis_luta_preservar_patente_remedios_india >. Acesso em: 02 jun. 2010.

SARLET, Ingo Wolfgang. Direitos fundamentais sociais e proibição de retrocesso: algumas notas sobre o desafio da sobrevivência dos direitos sociais num contexto de crise. In: (Neo) constitucionalismo. Porto Alegre: Instituto de Hermenêutica Jurídica, 2003.

Data de submissão: 13 de maio de 2013 Avaliado em: 14 de abril de 2014 (Avaliador A) Avaliado em: 22 de julho de 2014 (Avaliador B)

Aceito em: 29 de agosto de 2014 
